A concept called work centrality is developed to represent the generalized importance of working to individuals. Work centrality results for national samples of the labor force in Japan and in the United States are presented. A large difference is found between the measured work centrality levels in Japan and the United States. Several potential explanatory rationales are examined concerning this large work centrality difference.

\title{
WORK CENTRALITY IN JAPAN AND THE UNITED STATES
}

\author{
GEORGE W. ENGLAND \\ University of Oklahoma \\ JYUJI MISUMI \\ Osaka University
}

\section{THE IMPORTANCE OF WORKING}

There is widespread recognition that the activity of working and the outcomes flowing from working are of fundamental significance to most individuals. In Japan and the United States (as in most industrialized societies), the average employed person spends approximately one-third of his or her waking hours in the activities that are known as "working." Additionally, the time one spends in training and preparation for work, seeking work, and planning for a changed work situation suggest that work-related activities constitute a major utilization of time in the adult life. Connected to this timeutilization feature of working is the fact that a majority of

\footnotetext{
AUTHORS' NOTE: We express appreciation to the eight-country Meaning of Working International Research Team for long-term cooperation on the MOW project. For an initial description of the project, identification of participating researchers, research design statements, and instrumentation procedures, see MOW International Research Team, (1981). For comparative international results, see MOW International Research Team (in press).
}

JOURNAL OF CROSS-CULTURAL PSYCHOLOGY, Vol. 17 No. 4, December 1986, 399-416 ๑ 1987 Western Washington University 
individuals in these two societies derive the major part of their economic well-being from income and fringe benefits generated by their work activities.

Working and outcomes from working also provide noneconomic benefits to individuals. Were this not the case, it would seem impossible to explain why $65 \%$ to $95 \%$ of individuals in national labor force samples in a variety of countries (including the United States and Japan) state that they would continue to work even if "they had enough money to live comfortably for the rest of their life without working" (MOW International Research Team, 1986; Vecchio, 1980; Warr, 1982). This stated preference for working even when financial necessity is presumed not to be a major consideration is undoubtedly related to the broader social value or significance individuals attach to working as demonstrated in studies such as Morse and Weiss, (1955, p. 191) in which most respondents indicated that "working gives them a feeling of being tied into the larger society, of having something to do, and of having a purpose in life."

Working activities and situations also have the potential to generate negative consequences and outcomes for individuals, and this factor must affect the work importance calculus. Working can be experienced as boring, dull, or unchallenging at one end of the spectrum or as excessively overloaded at the other; it can result in frustration, dissatisfaction, stress, or inadequate person-job fit and may impact negatively on both mental and physical health. Cooper and Payne $(1978,1980)$ have recently summarized much of this relevant literature.

The general significance of working to individuals also is indicated by 50 years of research concerning the impact of unemployment and retirement on people who have been productive and active during their lives (Aiken, Ferman, \& Sheppard, 1968; Dooley \& Catalano, 1980; Friedmann \& Havighurst, 1954; Hepworth, 1980; Israeli, 1935; Jahoda, 1979; Kaplan \& Tausky, 1974; Parnes \& King, 1977, Warr, 1983; Wilensky, 1961). If the nonworking person cannot find some other meaningful set of activities in which to become 
involved, the effects of inactivity, idleness, and work outcome loss often are very demoralizing and dehabilitating. Studs Terkel (1972, p. 44) presents dramatic testimony to the identity loss suffered by an unemployed 45-year-old construction worker:

Right now I can't really describe myself because . . . I'm unemployed ... So, you see, I can't say who I am right now ... I guess a man's something else besides his work, isn't he? But What? I just don't know.

Working, then, would seem to be of general significance to the individual because it occupies a great deal of his or her time, because it generates economic and sociopsychological benefits and costs, and because it is so interrelated with other important life areas such as family, leisure, religion, and community.

\section{THE CONCEPT OF WORK CENTRALITY}

Given all of this recognition about the general importance of working in the lives of most individuals, it is not surprising that scholars and researchers have focused attention on a variety of concepts and measurement procedures to assess and study the importance of working. Morrow (1983), for example, reviewed research in the area of work commitment and classified five major approaches to studying work commitment that, respectively, focus attention on values, careers, jobs, employing organizations, and unions. The "central life interest" studies of Dubin and colleagues (Dubin, 1956; Dubin, Champoux, \& Porter, 1975; Dubin, Hedley, \& Taveggia, 1976) were most useful in the present development, whereas Siegel (1983) has presented independent but similar reasoning to that presented here.

This article focuses on the development of a concept concerning the generalized importance of working and an empirical application in the labor forces of Japan and the 
United States. The concept is named work centrality. Work centrality is defined as the degree of general importance that working has in the life of an individual at any given point in time.

We are in agreement with the conceptual distinction that Kanungo (1982) makes between work involvement and job involvement and with his argument to separate measurement of the state of involvement (work centrality, in our case) from its antecedents. Thus we do not single out any a priori reason why working should be important in one's life or in what way it is important in one's life and attempt to have work centrality represent that particular rationale for work importance; rather, we purposely choose to be neutral toward all potential rationales for the importance of work. Working may be important to one individual primarily because of economic benefits received from working, to another primarily because of sociopsychological benefits obtained through the process of working, or most likely because of some combination of a variety of rationales. Our concept of work centrality, therefore, must encompass these differing individual rationales for work importance, but our measurement procedures must be neutral to the differing rationales.

\section{THE MEASUREMENT OF WORK CENTRALITY}

Although there are several measurement procedures that could be used to assess the general importance of working in an individual's life (see Kanungo, 1982, for three recent measurement devices), we developed a procedure by which the importance of working is directly compared with the importance of other major life areas. The evaluative frame of reference in this procedure is a complex but structured frame of reference involving self and working versus self and other major life areas. The primary intended characteristics of the measurement procedure are comparative in nature and involve cognitive, decision-making, and affective elements. Figure 1 shows the primary work centrality measurement device utilized 
in the present study and presents general results about the relative importance of major life areas in each country.

Although the data shown in Figure 1 can be viewed from a number of interesting perspectives, several observations are most relevant to the issue of work importance. The Japanese sample assigns the most points to the life area of "working" and only slightly fewer to the area of "family." The American sample assigns about the same number of points to "family" as does the Japanese sample but assigns considerably fewer points to "working." Whether looked at within a country but across life areas or within the life area of "working" but across countries, the importance of working appears to be substantially greater in Japan than in the United States.

The measurement procedure shown in Figure 1 allows the development of two related indicators of work centrality for any individual. The first is simply the number of points assigned to response option $\mathrm{C}$ (My Work), which can vary from 0 to 100 points for any individual. If one uses the number of points assigned to (My Work) by an individual as an indicator of work centrality, it usually becomes necessary to use characteristics of some distribution of scores for attaching interpretive meaning to that score. For example, when a person assigns 22 points to work; initial interpretive meaning is usually generated by observing where this score of 22 stands with respect to some relevant sample of individuals (is it high, average, or low?).

The second indicator of work centrality that can be derived from the measurement procedure shown in Figure 1 is one that represents the ordinal position of work for a given individual among the five life areas that are evaluated in relative importance. For any individual, work may be the most important life area (that is, more points are assigned to it than to any other life area), second most important life area, third, fourth, or least important life area. Certain standard decision rules can be (and have been) adopted to handle situations in which there are ties in the number of points assigned to two or more life areas and the result is the ordinal importance position 


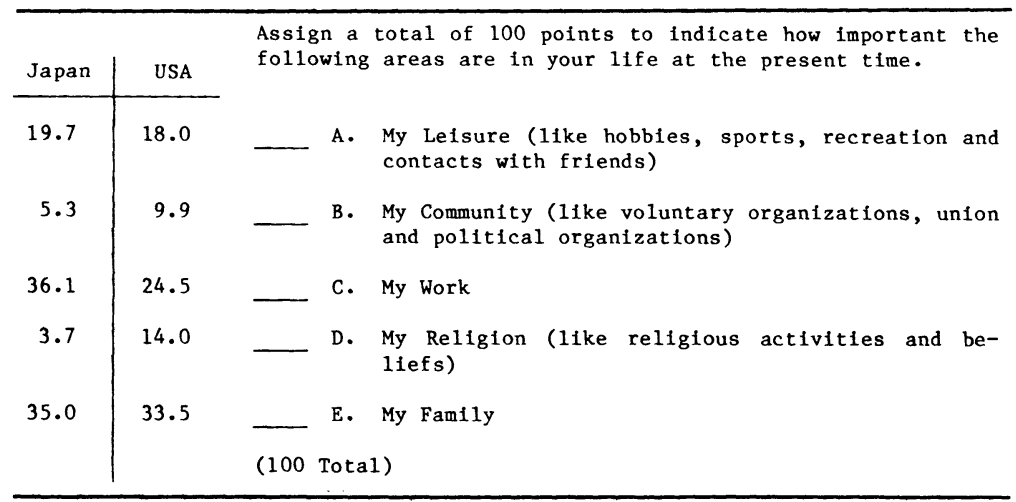

Figure 1: Work centrality measure with the mean number of points assigned to each of the major life areas in each country.

of work among the life areas for any given individual. ${ }^{1}$

This ordinal measure of work centrality appears to provide two advantages over the "number of points" measure. First, such a categorical score is likely to be more stable over the time than is the point score. Second, the ordinal or rank score of the importance of work in one's life has some idiographic meaning in and of itself without reference to any normative sample. If work has a rank of one, we know that working is more important for that individual than any of the other life areas, and from this there is inferential meaning that is not dependent upon how others view the importance of work. A similar case can be made for any other importance rank for working, although the argument becomes less persuasive as one moves away from the extreme ranks. The ordinal measure of work centrality, then, relies on differences in importance between life areas for a given individual for initial inferences about interpretive meaning. Use of the number of points assigned to work as a measure of work centrality relies largely on differences between individuals in points assigned to work for inferences about interpretive meaning. We believe that the ordinal procedure has high potential for scientific utility because it allows one to distinguish between meaning derived from idiographic as contrasted to normative measurement 
aspects. One can legitimately focus on either the idiographic or the normative aspects or upon both for interpretation, but placing initial emphasis on the idiographic assures that both aspects can be considered separately.

The measurement procedure just described whereby centrality is assessed in terms of the ordinal position of work among a set of important life areas coincides closely with the stated conceptual meaning of work centrality, it relies upon a relatively stable measurement process, and it is interpretable at the level of the individual or at the group level. When dealing with aggregations of individuals, the focus is on the relative incidence of defined ordinal levels of work centrality in the aggregation.

\section{WORK CENTRALITY IN JAPAN AND THE USA}

The previously described concept of work centrality and its measurement as the ordinal importance position of work among a set of five significant life areas is used as one major variable in comparing the meaning of working in Japan and the United States. In these two countries, a total of 4,228 individuals provided detailed information about the meaning of working to them. The data were collected through structured interviews administered by professional interviewers during 1982. ${ }^{2}$ The respondents were a stratified random sample of each country's employed labor force. Table 1 provides a common description of the composition of each country's sample. As noted in Table 1, there are some differences between the two samples in most characteristics. These, however, largely reflect actual labor force composition differences as opposed to sampling biases.

Table 2 shows the ordinal level of work centrality results for the two countries. As shown in the first two columns of Table 2, there are clear-cut differences between the two countries in the incidence of various work centrality levels. The largest percentage difference occurs at the level of work being the most 
TABLE 1

Description of Japanese and U.S. National Samples

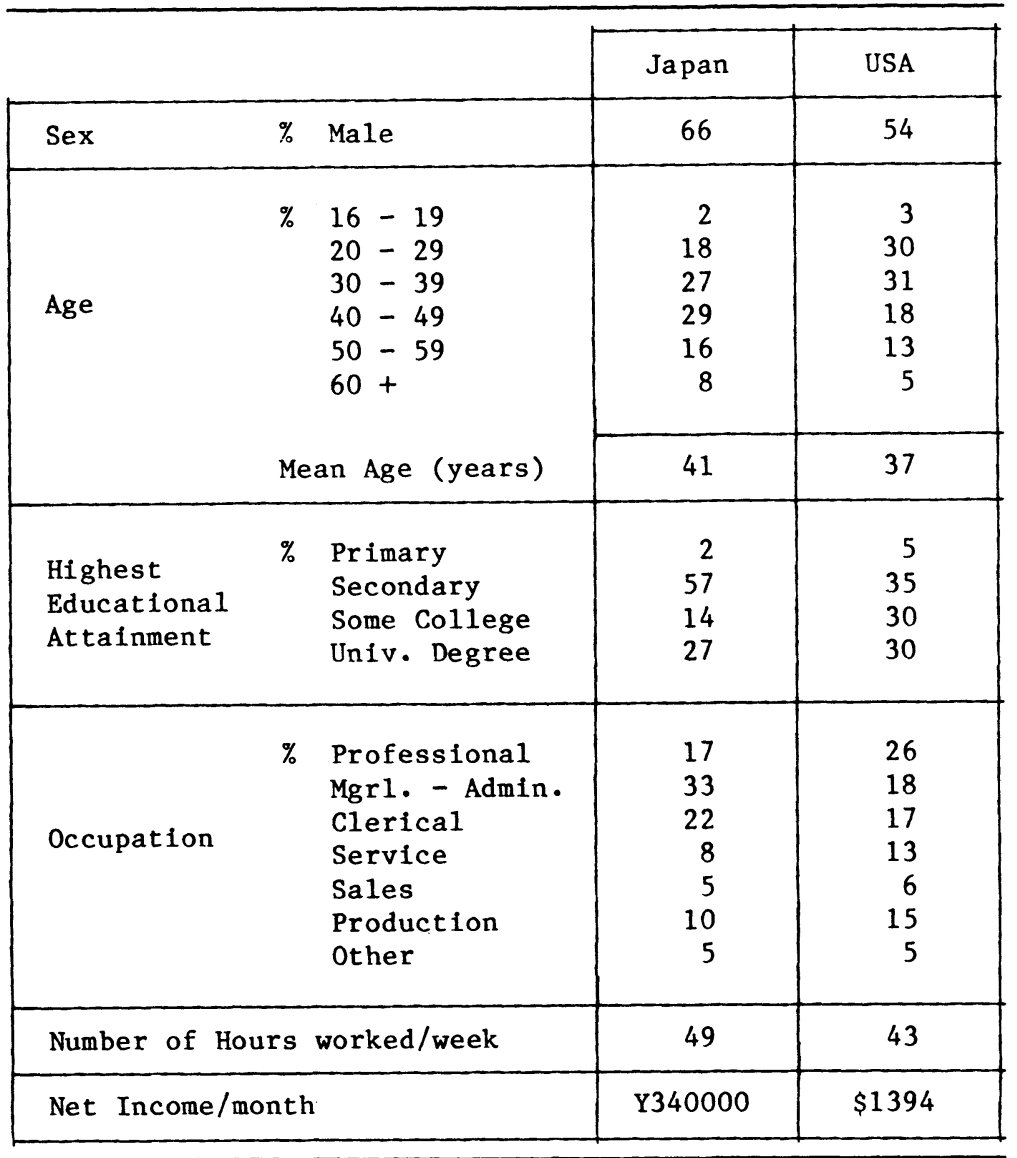

NOTE: Each country interviewed a stratified random sample of the working labor force in their respective country. Sample sizes were Japan, 3,226; United States, 1,002 .

important life area where the incidence for the Japanese sample is over twice that for the U.S. sample. The incidence difference between the two countries at the second level of work centrality is relatively small, although Japan still has a slightly higher incidence. 
TABLE 2

Incidence of Work Centrality Levels Within Japan and the United States

\begin{tabular}{l|c|c|c|c|}
\hline \multirow{2}{*}{} & \multicolumn{2}{|c|}{$\begin{array}{c}\text { Percentage } \\
\text { Frequency }\end{array}$} & \multicolumn{2}{|c|}{$\begin{array}{c}\text { Mean No. Points } \\
\text { Assigned to Work }\end{array}$} \\
\cline { 2 - 5 } Work Centrality Level & Japan & USA & Japan & USA \\
\hline Work is most important & $37.3 \%$ & $16.7 \%$ & 55 & 45 \\
Work is 2nd most important & 34.1 & 29.5 & 34 & 29 \\
Work is 3rd most important & 18.5 & 31.8 & 19 & 20 \\
Work is 4th most important & 9.0 & 14.8 & 6 & 12 \\
Work is least important & 1.1 & 7.2 & 3 & 8 \\
\hline
\end{tabular}

a. Probability that the distributions are not significantly different $<.00001$.

The incidence patterns "cross over" between levels 2 and 3 and the United States a substantially higher incidence than Japan at the three lower levels of work centrality. The work centrality concept as defined and measured identifies group similarities and differences in terms of idiographically defined work centrality levels. One also has the opportunity to focus attention upon the levels(s) of work centrality that are of primary theoretical or practical concern. For some purposes such as expected problems in adjusting to retirement, we might primarily be interested in those for whom work was among the most important life roles. For study of potential apathy at work or alienation from work, we might wish to focus only on those who view work as among the least important of the life roles.

The last two columns in Table 2 show the mean number of points assigned to work (out of a possible 100) for the various work centrality levels in the two countries. Because this value is a major element used in classifying the work centrality level of an individual, the decreasing point patterns shown are expected. The mean values are useful, however, in providing a generally consistent indication of what the five levels of work centrality represent in terms of points (out of 100) assigned to 
work. On the average, assignment of about one-half of the 100 points to work characterizes individuals for whom work is the most important life role. The same characterization for work centrality levels 2 through 5 are about one-third of the points, one-fifth of the points, one-ninth of the points, and oneeighteenth of the points, respectively. Clearly, the work centrality levels are quite different in definitional character; the highest level is indeed high and the lowest level is indeed low.

Two empirical conclusions come from analysis of various work importance indicators in Japanese and American labor force samples. ${ }^{3}$ First is the general conclusion that working is indeed a major and important life area in both countries. Over one-half of the Japanese sample and one-third of the U.S. sample assign a number of points to work that is greater than or equal to that assigned to any other major life area. On a 7-point rating scale of the importance of working in one's life where 1 represented "one of the least important things in my life" and 7 represented "one of the most important things in my life," the highest possible value (7) was the response for $45 \%$ of the Japanese sample and $30 \%$ of the American sample. In all, $93 \%$ of the Japanese sample and $88 \%$ of the American sample state that they would continue to work if they "won a lottery or inherited a large sum of money and could live comfortably for the rest of [their lives] without working." Clearly, working is perceived in both countries as an important and significant life area.

The second empirical conclusion that comes from the previously cited analyses of work importance indicators in the two national samples is that working is a more important part of life for the Japanese labor force than for the American labor force. The magnitude of this difference between the two countries in work centrality is substantial and would seem to represent a "strong" finding. The same general finding (although expressed and measured differently) has consistently been reported in the literature for over 25 years. Whitehill and Takezawa (1968) showed that Japanese blue-collar workers in 1960 valued working at higher levels of capacity and placed 
their company in a far more central life role than did their American counterparts. The same authors (Takezawa \& Whitehill, 1981) reported that these differences increased in the 16-year period between their two studies. England (1975) reported that both organizational goals and personal achievement goals were more behaviorally relevant for Japanese than for American managers. More general works by Vogel (1963), Cole (1971), Kahn and Pepper (1979), Marsh and Mannari (1976), Ouchi (1981), and Pascale and Athos (1981) support this same general conclusion.

\section{IMPLICATIONS}

Given the consistently reported large difference in the importance of working in the lives of Japanese and American labor forces in general and for some occupational groups, we would hypothesize that the presently reported difference is more a national level phenomenon than an occupational one.

Figure 2 shows the relative importance of work as a life role for different occupational groups in Japan and the United States. For ease of data presentation, we will utilize the number of points (out of 100) assigned to work as the indicator of work importance. In the present context, two points should be made. First, work is significantly more important $(\mathrm{p}<.001)$ for every occupational group of Japanese workers when compared with the same occupational group in the United States. Second, occupational differences in the importance of working within each country are relatively small when compared with the overall national level difference. The average difference between pairs of occupational groups in Japan is 3.4 points and the average difference between pairs of occupational groups in the United States is 2.4 points. These occupational differences can be compared with the national level difference in points assigned to work, which is 11.6 points (Japan $=36.1$, United States $=24.5$ ). Thus it is clear that the national level difference in work importance between Japan and the United States is 


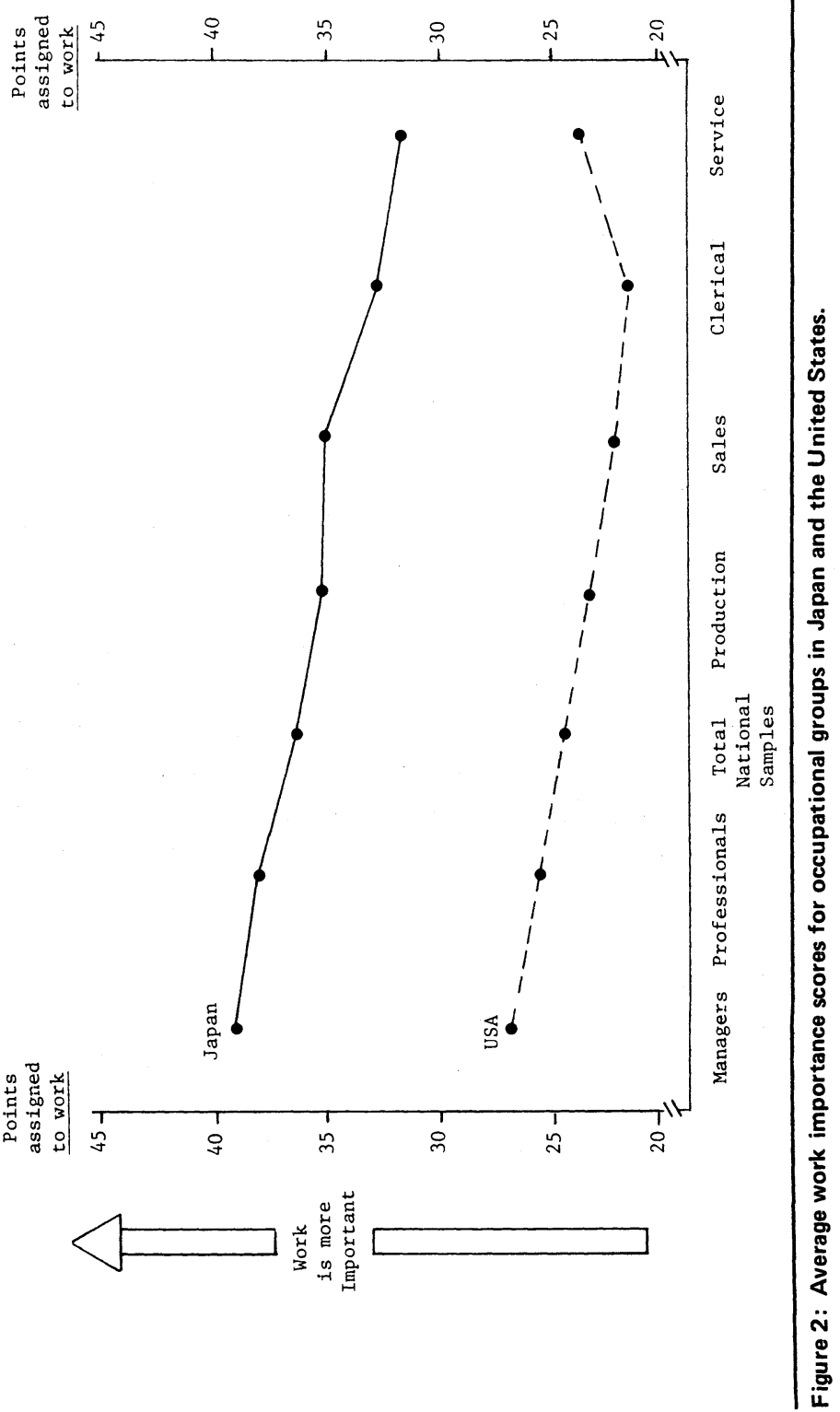


three to four times as large as average occupational differences within each country. This provides confirmation for the hypothesis that the substantial work importance differences between Japan and the United States more a national phenomenon than an occupational one.

A second implication is derived from the time period when this difference in work importance seems to become most evident in the lives of workers. Figure 3 shows that the difference in the importance of working between Japanese and Americans is not large for students about ready to begin working (data collected separately from the national surveys) and for beginning workers under 20 years of age. For U.S. workers, there is a small but steady increase in the importance of work in one's life from the earliest age (under 20) to the 50's and then a decline in the oldest age group. ${ }^{4}$ For the Japanese sample, the importance of work in one's life increases dramatically during the $20 \mathrm{~s}$, and from thereafter the amount of difference between the two countries remains relatively consistent. Although these results from cross-sectional data analyses, it can be suggested that: (1) Japanese organizations may do an effective job of socializing workers to the importance of the working role during their first 10 years of employment, (2) the major part of the Japan-United States difference in work centrality comes about during this early period of work life, and (3) this difference is maintained at all older age classifications. Work importance for at least Japanese males seems to be significantly enhanced by early career training and socialization. It is probably the case that the conditions conducive to early and effective work importance socialization in Japan are aided by the collective nature of Japanese society, whereas the individualistic nature of American society would weigh heavily against the likelihood than any uniform means of work socialization could be effective (see, Hofstede, 1980).

Finally, a more general and speculative implication concerns a potential explanation for the large work importance difference between the two countries. This explanation is perceptual in character and suggests that Japanese may per- 


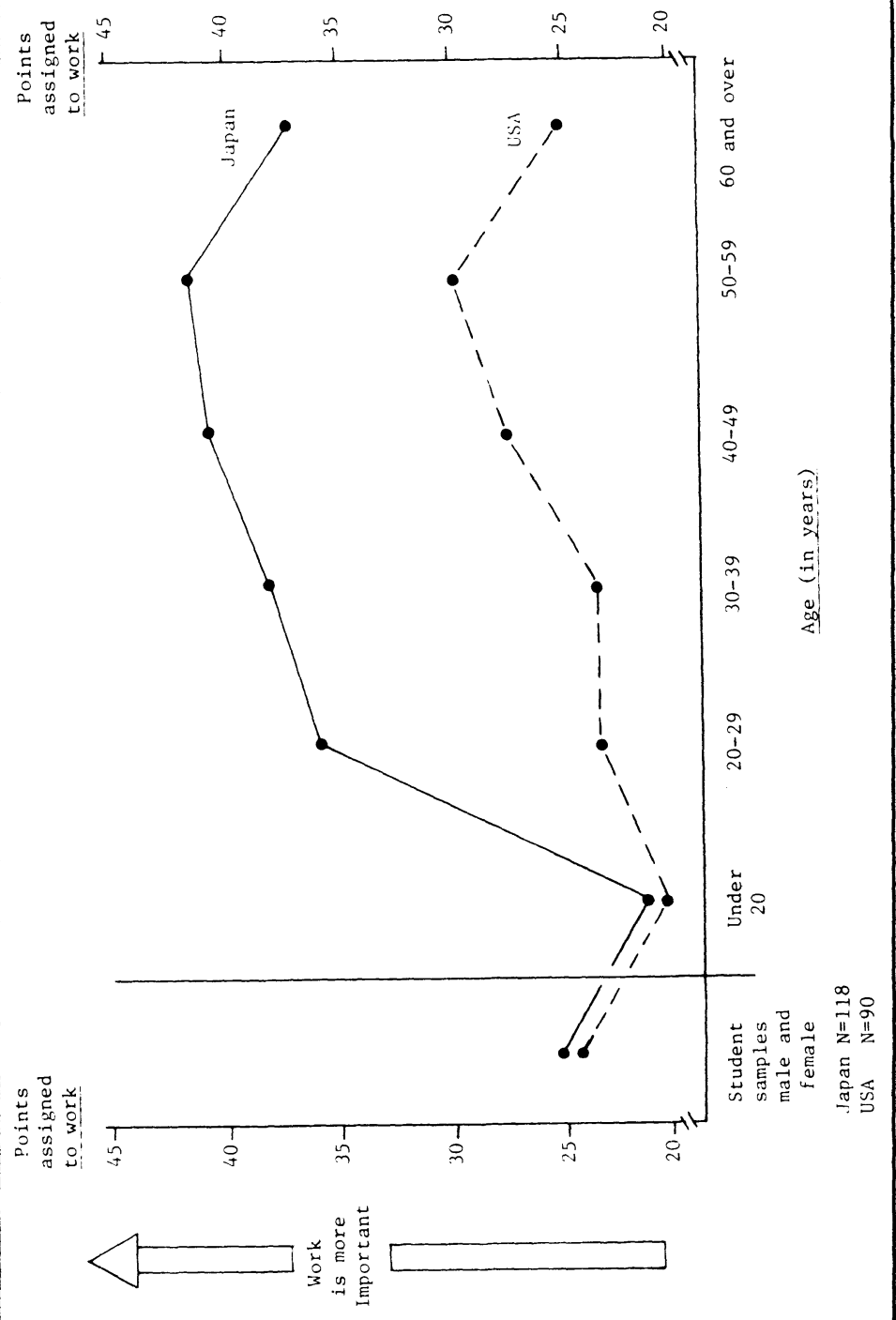

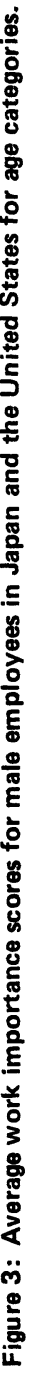


ceive less certainty than do American workers that long-term economic well-being will continue to be favorable for them in the future. This explanation implies that the Japanese labor force recognizes or comes to recognize early in their work life that their country is relatively poor in natural resource endowment. Working harder or smarter as individuals and in larger collectivities is an adaptive response to this fear of economic decline. American workers may not perceive the same necessity to work harder or smarter given that the United States has more abundant natural resource endowment and has occupied a favorable economic position in the world for nearly half a century (see, England, 1983, for a more complete discussion of this rationale).

All of these implications again lead us to believe that work centrality is a powerful theoretical concept and that the most important work meaning difference between Japan and the United States is indeed the difference in the incidence of various work centrality levels between the two countries. This is a major difference between labor force members in the two countries whose understanding is worthy of sustained research effort.

\section{NOTES}

1. The decision rules were based on the number of life areas the respondent gave (a) fewer points than working, (b) points equal to working, and (c) more points than working. Because there are five life areas (including work), there are 15 possible scoring combinations. The decision rule adopted (and confirmed by a biplot of the 15 $\times 3$ matrix that has a row for each possible score and columns as noted in $\mathrm{a}, \mathrm{b}, \mathrm{c}$ above) is as follows: if working ranked first (all other life areas were given fewer points than work), the response is scored as 5; a rank of second (one life area given more points than work and the rest fewer, or no life areas given more points than work but one or two areas equal to work) scored 4; third (two life areas greater than work, one greater and one or two equal, or none greater but three or all four others equal) was scored 3; fourth (three greater, two greater and one or two equal or one greater and two or three equal) scored 2; and fifth (four greater than work, or three greater and one equal) scored 1 .

2. The MOW project employed a decentralized collective research framework according to which collaborators from all countries jointly participated in the design, 
development, implementation, and analysis of the project. Problems of translation always exist in cross-national research and must be faced. Because the underlying concepts and the structured interview questionnaires themselves were jointly developed by the MOW team and pilot tested in each country over a three-year period, there was a high level of understanding that could be utilized in translation. The questionnaire was originally framed in English and then translated into the appropriate language (Japanese in the present case) by the national research team and professional translators. Then "back-translation" was used that involved the independent translation from each language back into English. The back-translation and the original were compared, and where necessary, the translated version was adjusted. The one translation error in the Japanese language version that has become known to the investigators is of minor significance and not involved in the present analysis.

3. Complete data on these alternative measures of work importance are reported in MOW International Research Team (1986, chapter 5). Various combinations of indicators of work importance also support the same two empirical conclusions.

4. We present data in Figure 3 only for the males from each country's national sample to obviate the clear problem concerning work opportunity differences as related to age between males and females in Japan. Sex differences in work importance levels are large in Japan but inconsequential in the United States according to our data. Thus, male comparisons between the two countries probably have more validity for the type of inferences being made. Student samples shown in Figure 3 include both males and females in approximately equal proportion.

\section{REFERENCES}

Aiken, M., Ferman, L., \& Sheppard, H. L. (1968). Economic failure, alienation and extremism. Ann Arbor: University of Michigan Press.

Cole, R. E. (1971). Japanese blue collar, the changing tradition. Berkeley: University of California Press.

Cooper, C. L., \& Payne R. (1978). Stress at work. New York: John Wiley.

Cooper, C. L., \& Payne R. (1980). Current concerns in occupational stress. New York: John Wiley.

Dooley, D., \& Catalano, R. (1980). Economic change as a cause of behavioral disorder. Psychological Bulletin, 87, 450-468.

Dubin, R. (1956). Industrial workers' worlds: A study of the "central life interests" of industrial workers. Social Problems, 3, 131-142.

Dubin, R., Champoux, J. E., \& Porter, L. W. (1975). Central life interests and organizational commitment of blue-collar and clerical workers. Administrative Science Quarterly, 20, 411-421.

Dubin, R., Hedley, R. A., \& Taveggia, T. C. (1976). Attachment to work. In R. Dubin (Ed.), Handbook of work, organization, and society (pp. 281-342). Chicago: Rand-McNally.

England, G. W. (1975). The manager and his values: An international perspective. Cambridge: Ballinger. 
England G. W. (1983, Fall). Japanese and American management: Theory Z and beyond. Journal of International Business Studies, pp. 131-142.

Friedmann, E. A., \& Havighurst, R. J. (1954). The meaning of work and retirement. Chicago: University of Chicago Press.

Hepworth, S. J. (1980). Moderating factors of the psychological impact of unemployment. Journal of Occupational Psychology, 53, 139-145.

Hofstede, G. (1980). Culture's consequences: International differences in work-related values. Beverly Hills CA: Sage.

Israeli, N. (1935). Distress in the outlook of Lancashire and Scottish unemployed. Journal of Applied Psychology, 19, 67-69.

Jahoda, M. (1979, September). The psychological meanings of unemployment. New Society, pp. 492-495.

Kahn, H., \& Pepper, T. (1979). The Japanese challenge. New York: Crowell.

Kanungo, R. N. (1982). Measurement of job and work involvement. Journal of Applied Psychology, 67, 341-349.

Kaplan, H. R., \& Tausky, C. (1974). The meaning of work among the hard core unemployed. Pacific Sociological Review, 17, 185-198.

Marsh, R. M. \& Mannari, H. (1976). Modernization and the Japanese factory. Princeton: Princeton University Press.

Morrow, P. C. (1983). Concept redundacy in organizational research: The case of work commitment. The Academy of Management Review, 8, 486-500.

Morse, N. C., \& Weiss, R. C. (1955). The function and meaning of work and the job. American Sociological Review, 20, 191-198.

MOW International Research Team. (1981). The meaning of working. In G. Dlugos \& K. Weiermair (Eds.), Management under differing value systems: Political, social and economical perspectives in a changing world (pp. 565-630). New York: Walter De Gruyter.

MOW International Research Team. (in press). The meaning of working: An international perspective. New York: Academic Press.

Ouchi, W. (1981). Theory Z: How American business can meet the Japanese challenge. Reading, MA: Addison-Wesley.

Parnes, H. S., \& King, R. (1977). Middle-aged job losers. Industrial Teronotology, 4, 77-95.

Pascale, R. T., \& Athos, A. G. (1981). The art of Japanese management: Applications for American executives. New York: Simon \& Schuster.

Siegel, I. H. (1983). Work ethic and productivity. In J. Barbash, R. Lampman, S. Levitan, \& G. Tyler (Eds.), The work ethic-a critical analysis. Madison, WI: Industrial Relations Research Association.

Takezawa, S., \& Whitehill, A. M. (1981). Work ways: Japan and America. Tokyo: Japan Institute of Labour.

Terkel, S. (1972). Working. New York: Pantheon.

Vecchio, R. P. (1980). The function and meaning of work and the job: Morse and Weiss (1955) revisited. Academy of Management Journal, 23, 361-367.

Vogel, E. F. (1963) Japan's new middle class. Berkeley: University of California Press.

Warr, P. B. (1982). A national study of non-financial employment commitment. Journal of Occupational Psychology, 55, 297-312. 
Warr, P. B. (1983). Work and unemployment. In P. Drenth, H. Thierry, P. Willems, \& C. de Wolff (Eds.), Handbook of work and organization psychology. London: John Wiley.

Whitehill, A. M., \& Takezawa, S. (1968). The other worker: A comparative study of industrial relations in the United States and Japan. Hawaii: East-West Center Press.

Wilensky, H. L. (1961). Orderly careers and social participation: The impact of work history on social integration in the middle mass. American Sociological Review, 26, 521-539.

George W. England is Professor of Management and Director of the Center for Economic and Management Research in the College of Business Administration at the University of Oklahoma (Norman, OK 73019, U.S.A.). Professor England is author or coauthor of several books in the area of organizational psychology and management, including The Manager and the Man, Organizational Functioning in a Cross-cultural Perspective, The Functioning of Complex Organizations, and The Meaning of Working: An International Perspective.

Jyuji Misumi is Professor of Psychology at the Faculty of Human Sciences, Osaka University, Japan. Professor Misumi has authored or coauthored nearly 50 books in the area of group dynamics and leadership including The Behavioral Science of Leadership, Group Dynamics, New Leadership in Administrative Organization, and The Meaning of Working: An International Perspective. 